\title{
The hygrothermal performance of concrete with coarse aggregates made of recycled concrete pavements
}

\author{
Václav Kočí1,*, Magdaléna Doleželová ${ }^{1}$, Lukáš Fiala ${ }^{1}$, and Tomasz Tracz ${ }^{2}$ \\ ${ }^{1}$ Czech Technical University in Prague, Faculty of Civil Engineering, Department of Materials \\ Engineering and Chemistry, Thákurova 7/2077, 16629 Prague 6, Czech Republic \\ ${ }^{2}$ Cracow University of Technology, Faculty of Civil Engineering, Chair of Building Materials \\ Engineering, 24 Warszawska St., 31-155 Cracow, Poland
}

\begin{abstract}
This paper deals with an investigation of the hygrothermal performance of concretes containing various amounts of recycled aggregates originating from crushed concrete pavements. The performance, which was obtained using computational modelling of coupled heat and moisture transport, is predicted on stand-alone samples as well as on builtin samples in a real construction exposed to weather data of Ostrava, Czech Republic. The results revealed that the influence of recycled aggregates as substitution for natural stone does not negatively affect the hygrothermal performance of the concrete. The highest difference found was less than $1{ }^{\circ} \mathrm{C}$ and $12 \%$ of $\mathrm{RH}$ in the case of stand-alone samples and only $2.2 \%$ of $\mathrm{RH}$ when built in. Therefore, the application of crushed concrete pavements as aggregates in concrete composition can be highly recommended as it brings other benefits such as economical and environmental.
\end{abstract}

\section{Introduction}

Current trends in building material engineering are primarily aimed at the development of products, which are supposed to be as environmentally friendly as possible [1,2]. This means that materials with excellent properties are being sought which provide the following benefits: the building of thinner constructions with the need for less material (with excellent mechanical properties) [3,4]; decreases to the operational costs during the constructions' service life (e.g. excellent thermal properties) [5, 6]; increases to the constructions' service life (various combinations of functional properties) [7]; the exploitation of special performance and properties (smart materials) [8,9]. Additionally, production processes are also being optimised as ways are sought for how to minimise requirements for primary resources. This involves the utilisation of waste or recycled materials, in particular $[3,10$, $11]$.

The production of concrete, which represents the worst global environmental load when compared to the production of other building materials, has been affected by all the

\footnotetext{
* Corresponding author: vaclav.koci@ fsv.cvut.cz
} 
aforementioned trends as it is a very versatile material that allows many modifications. One can therefore use concretes with excellent mechanical, thermal or hygric properties. Moreover, various waste products have been used to partially replace the original compounds that concretes are made of. These efforts are especially evident in the case of cement which is partially substituted by blast furnace slag [12, 13], silica fume [14, 15], fly ash [16, 17] or other less energy-demanding material alternatives that exhibit certain pozzolanic properties. However, the primary resource savings can also be achieved in the case of other compounds such as aggregates.

This paper deals with the investigation of concrete with various amount of aggregates substituted with crushed concrete pavement (recycled aggregates). It exploits a computational modelling technique to evaluate the hygric and thermal performance of the concretes themselves and of the same concretes being built in a selected application The main objective is to quantify the influence of recycled aggregates and its amount on the hygrothermal performance of concrete as well as the selected construction detail.

\section{Materials and methods}

\subsection{Studied concretes}

The investigated concretes are made of the same amount of cement (CEM I $42.5 \mathrm{R}, 414.2$ $\left.\mathrm{kg} / \mathrm{m}^{3}\right)$ and water $\left(186.4 \mathrm{~kg} / \mathrm{m}^{3}\right)$, providing the $w / c$ ratio of 0.45 . The mixtures also contain plasticizer BASF BV 18 (0.9\% by mass) and BASF Glenium SKY 591 (1.4\% by mass). The particular mixtures differ in the amount and type of aggregates as specified in Table 1.

Table 1. Aggregates used for particular mixtures.

\begin{tabular}{|c|c|c|c|}
\hline Type of aggregates & CR & C50 & C100 \\
\hline River sand 0/4 (Dwudniaki) & $615.1 \mathrm{~kg} / \mathrm{m}^{3}$ & $280.6 \mathrm{~kg} / \mathrm{m}^{3}$ & $569.2 \mathrm{~kg} / \mathrm{m}^{3}$ \\
\hline Coarse agg. 8/16 (Dwudniaki) & $579.9 \mathrm{~kg} / \mathrm{m}^{3}$ & $280.6 \mathrm{~kg} / \mathrm{m}^{3}$ & - \\
\hline Coarse agg. 4/16 (Dwudniaki) & $562.3 \mathrm{~kg} / \mathrm{m}^{3}$ & $264.1 \mathrm{~kg} / \mathrm{m}^{3}$ & - \\
\hline Recycled concrete agg. $4 / 16$ & - & $825.3 \mathrm{~kg} / \mathrm{m}^{3}$ & $1057.2 \mathrm{~kg} / \mathrm{m}^{3}$ \\
\hline
\end{tabular}

\subsection{Computational modelling of hygrothermal performance}

The computational modelling approach serves as a tool for the assessment of the hygrothermal performance of particular concretes: stand-alone to highlight differences between particular materials; built in a selected construction detail to show their performance and interactions as a part of a system. The schemes of the studied details are given in Fig. 1 including the mesh parameters and the scheme of applied boundary conditions. 


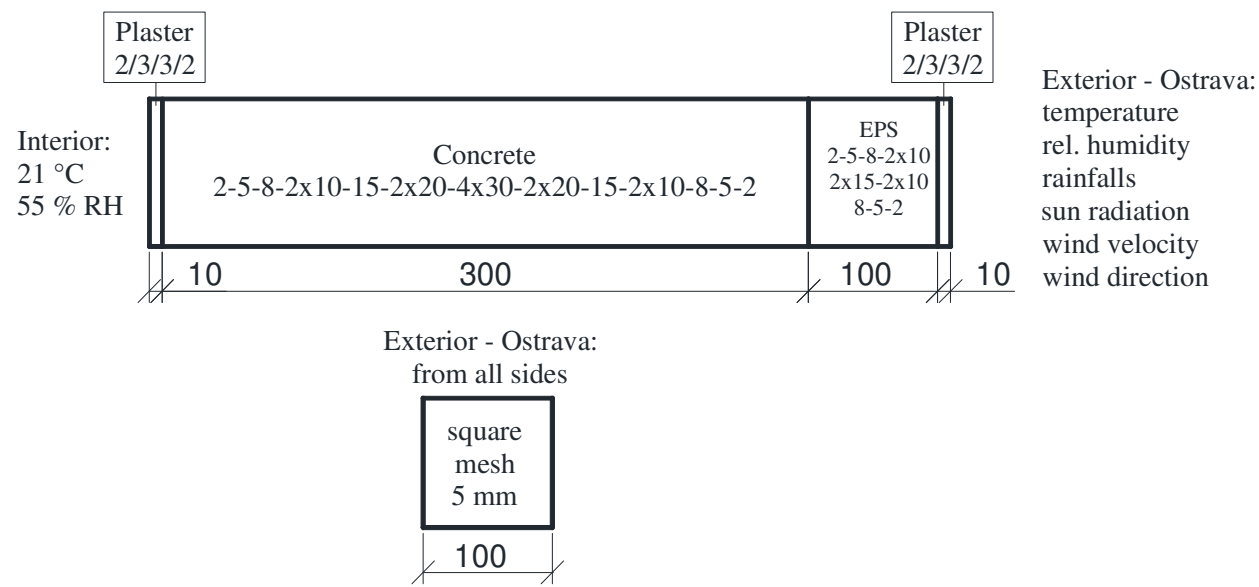

Fig. 1. Scheme of analysed details including mesh parameters and boundary conditions.

The coupled heat and moisture distribution, induced by dynamic boundary conditions, is calculated using the diffusion mathematical model (see Eqs. (1)-(2)) described by Kočí et al. [18].

$$
\begin{aligned}
& \rho_{w} \frac{\mathrm{d} w}{\mathrm{~d} p_{v}} \frac{\partial p_{v}}{\partial t}=\operatorname{div}\left[\left(B D_{w} \rho_{w} \frac{\mathrm{d} w}{\mathrm{~d} p_{v}}+A \delta_{p}\right) \operatorname{grad} p_{v}\right], \\
& \frac{\mathrm{d} H}{\mathrm{~d} T} \frac{\partial T}{\partial t}=\operatorname{div}(\lambda \operatorname{grad} T)+L_{v} \operatorname{div}\left[A \cdot \delta_{p} \operatorname{grad}\left(p_{v}\right)\right],
\end{aligned}
$$

where $\rho_{\mathrm{w}}\left(\mathrm{kg} / \mathrm{m}^{3}\right)$ is the water density, $w\left(\mathrm{~m}^{3} / \mathrm{m}^{3}\right)$ is the water content, $p_{\mathrm{v}}(\mathrm{Pa})$ is the partial pressure of water vapor in the air, $t(\mathrm{~s})$ is the time, $D_{\mathrm{w}}\left(\mathrm{m}^{2} / \mathrm{s}\right)$ is the moisture diffusivity, $\delta_{\mathrm{p}}$ (s) is the water vapor permeability, $H\left(\mathrm{~J} / \mathrm{m}^{3}\right)$ is the enthalpy density, $T(\mathrm{~K})$ is the temperature, $\lambda(\mathrm{W} / \mathrm{m} / \mathrm{K})$ is the thermal conductivity, $L_{\mathrm{v}}(\mathrm{J} / \mathrm{kg})$ is the latent heat of evaporation of water and $A, B \in\langle 0 ; 1>$ are transition coefficients between the liquid and gaseous phases of water which give the weight to each phase according to the current moisture content.

The weather data for Ostrava, Czech Republic (see Table 2 for more details) was applied on the exterior side, while the constant temperature and relative humidity were applied on the interior side [19]. The boundary conditions were used in form of TRY (test reference year) which consists of long-term average hourly values of the parameters described in Fig 1.

Table 2. Selected weather parameters of Ostrava, Czech Republic.

\begin{tabular}{|c|c|c|c|c|c|}
\hline \multicolumn{2}{|c|}{ Parameter } & Value & \multicolumn{2}{c|}{ Parameter } & Value \\
\hline \multirow{4}{*}{ Temperature } & Maximal & $32.9{ }^{\circ} \mathrm{C}$ & & Average & $78.0 \%$ \\
\cline { 2 - 3 } \cline { 5 - 6 } & Minimal & $-21.6^{\circ} \mathrm{C}$ & \multirow{2}{*}{ Relative humidity } & $>90 \%$ & $2368 \mathrm{hrs}$ \\
\cline { 2 - 3 } \cline { 5 - 6 } & Average & $9.0{ }^{\circ} \mathrm{C}$ & & $<40 \%$ & $225 \mathrm{hrs}$ \\
\cline { 2 - 3 } & $>30{ }^{\circ} \mathrm{C}$ & $16 \mathrm{hrs}$ & \multirow{2}{*}{ Rainfalls } & Total & $700.2 \mathrm{~mm}$ \\
\cline { 2 - 3 } & $<0{ }^{\circ} \mathrm{C}$ & $1265 \mathrm{hrs}$ & & & \\
\hline
\end{tabular}


Beside the detail discretisation and boundary conditions, the model also requires material conditions as other input parameters (see Table 3). This data was measured in the laboratories of the Department of Materials Engineering and Chemistry, FCE CTU Prague and will be presented in a separate contribution at the MATBUD conference.

Table 3. Summary of material properties.

\begin{tabular}{|c|c|c|c|}
\hline Type of aggregates & CR & C50 & C100 \\
\hline Bulk density $\left(\mathrm{kg} / \mathrm{m}^{3}\right)$ & 2236 & 2192 & 2192 \\
\hline Thermal conductivity $(\mathrm{W} / \mathrm{m} / \mathrm{K})$ & $2.409-2.794$ & $1.842-2.299$ & $2.082-2.289$ \\
\hline Specific heat capacity $(\mathrm{J} / \mathrm{kg} / \mathrm{K})$ & 817 & 785 & 812 \\
\hline Hygroscopic moisture content $\left(\mathrm{m}^{3} / \mathrm{m}^{3}\right)$ & 0.091 & 0.110 & 0.105 \\
\hline Water absorption coefficient $\left(\mathrm{kg} / \mathrm{m}^{2} / \mathrm{s}^{0.5}\right)$ & 0.0080 & 0.0130 & 0.0045 \\
\hline Apparent moisture diffusivity $\left(\mathrm{m}^{2} / \mathrm{s}\right)$ & $7.134 \times 10^{-9}$ & $1.583 \times 10^{-8}$ & $1.456 \times 10^{-9}$ \\
\hline
\end{tabular}

The solution of the heat and moisture balance equation of the mathematical model leads to a set of partial differential equations which is solved numerically using the finite element method. The evaluation of the hygrothermal performance of particular concretes is performed on the basis of the hourly values of temperature and the relative humidity obtained in each node in the tenth year of the simulations, which is long enough to reach some kind of dynamic equilibrium. The utilization of computational modelling for a solution of coupled heat and moisture transport has become very common and various papers on this topic can be found [20-21].

\section{Results and discussion}

As shown in Table 4, the material properties of particular concretes are very similar, which also predisposes them to exhibit similar hygrothermal performance. This performance was demonstrated on the two-dimensional distribution of heat and moisture in the stand-alone samples exposed to dynamic weather conditions from all four sides. The average annual state values of the whole cubes including their selected material parameters are summarised in Table 4. The results were obtained as an average of the hourly values of the selected parameters in each node of the mesh when exposed to dynamic boundary conditions.

Table 4. Summary of the samples' performance.

\begin{tabular}{|c|c|c|c|}
\hline Parameter & CR & C50 & C100 \\
\hline Average temperature & $10.286^{\circ} \mathrm{C}$ & $10.284^{\circ} \mathrm{C}$ & $10.287^{\circ} \mathrm{C}$ \\
\hline Average relative humidity & $87.787 \%$ & $89.507 \%$ & $87.944 \%$ \\
\hline Average moisture content & $22.025 \% \mathrm{~m}^{3} / \mathrm{m}^{3}$ & $23.811 \% \mathrm{~m}^{3} / \mathrm{m}^{3}$ & $21.793 \% \mathrm{~m}^{3} / \mathrm{m}^{3}$ \\
\hline Average thermal conductivity & $2.480 \mathrm{~W} / \mathrm{m} / \mathrm{K}$ & $1.933 \mathrm{~W} / \mathrm{m} / \mathrm{K}$ & $2.120 \mathrm{~W} / \mathrm{m} / \mathrm{K}$ \\
\hline
\end{tabular}

It is obvious, that the average state parameters, the temperature in particular, are very similar. However, due to the different thermal conductivity of particular samples and the 
different specific heat capacities, the dynamics of temperature change can be different. This can be demonstrated on the graph in Fig. 2 that compares temperatures of particular samples in the centre as of $23^{\text {rd }}$ February of the reference year $\left(3339^{\text {th }}\right.$ day of the simulations). One can see the temperature difference between particular samples of up to $2.1^{\circ} \mathrm{C}$. However, these differences are still very small, reaching only $0.1^{\circ} \mathrm{C}$ on average during the reference year. The relative humidity differences were found to be slightly higher, reaching more than $3 \%$ on average within the reference year. The highest difference, $12.08 \%$ was found in June of the reference year - this is depicted in Fig. 2 within the June-July period.

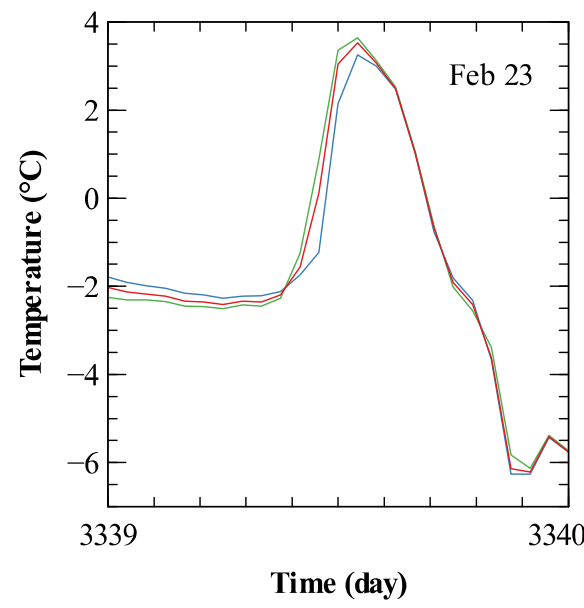

$\mathrm{CR}$

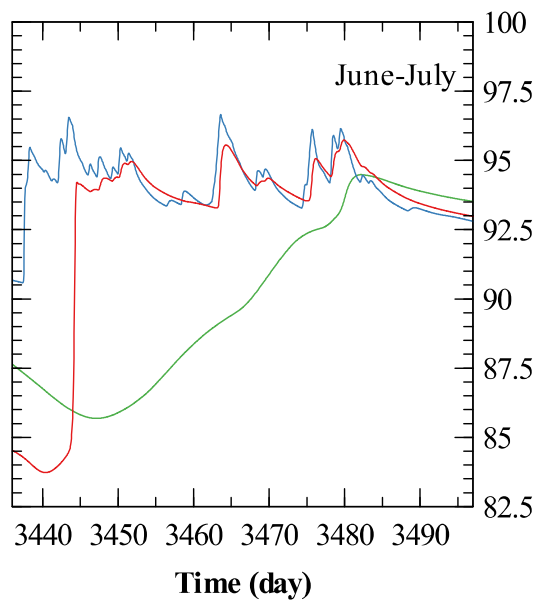

$\mathrm{C} 100$

Fig. 2. Comparison of the temperature and relative humidity evolution in the centre of the samples.

The dynamics of the response to changes in the boundary conditions also plays an important role in the performance of the building envelopes made of the studied materials. Since the differences found on stand-alone samples were relatively small, even smaller differences can be expected in case of the envelopes as the exterior and interior plasters act like a buffer and reduce the impact of the environment. Comparing the differences in temperature distributions, the highest was found $110 \mathrm{~mm}$ under the exterior surface as of $12^{\text {th }}$ January of the reference year, accounting only for $0.383^{\circ} \mathrm{C}$. The differences in relative humidity distributions are more visible but still very small. A value of $2.2 \%$ was found 17 $\mathrm{mm}$ under the exterior surface as of $27^{\text {th }}$ January. A comparison of the aforementioned profiles is given in Fig. 3. 


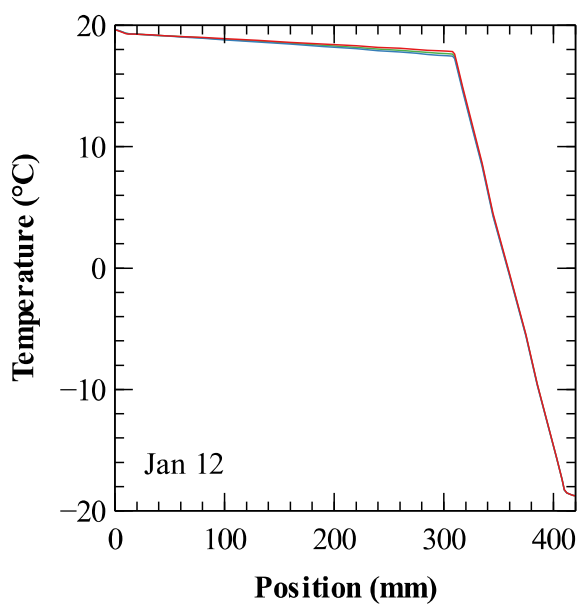

CR

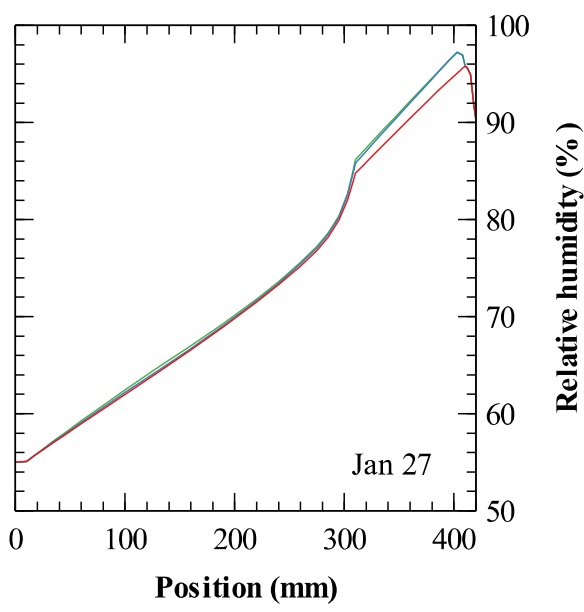

C50

$\mathrm{C} 100$

Fig. 3. Comparison of temperature and relative humidity profiles of the envelope studied on selected days; the position $0 \mathrm{~mm}$ denotes the interior side of the envelope and the position $420 \mathrm{~mm}$ denotes the exterior side.

Summarising all the facts presented so far, it can be concluded that all the studied concretes exhibited very similar hygrothermal performance. This means that the substitution of natural aggregates with crushed concrete pavements in various amounts did not have any effect on heat and moisture distribution. This measure can therefore be recommended as it might bring economical as well as environmental benefits. The quantification of these contributions is, however, beyond the scope of this paper and will be studied in a separate paper within the MATBUD 2020 conference.

\section{Conclusions}

This paper aimed to investigate the influence of recycled aggregates on the hygrothermal performance of concretes. Recycled aggregates originating from crushed concrete pavements were used to substitute $50 \%$ and $100 \%$ of natural stone. The particular samples were subjected to experimental analyses to determine their basic physical, heat and moisture properties that subsequently served as input data for computational modelling.

The hygrothermal performance was evaluated on the basis of the distribution of heat and moisture in the materials when exposed to dynamic boundary conditions. It was obtained using a diffusion type of mathematical model that was solved by means of the finite element method.

The results revealed that there is practically no influence of the recycled aggregates on the hygrothermal performance of the concrete. The highest difference during the reference year was found to be only $2.1^{\circ} \mathrm{C}$ and $12.1 \%$ of $\mathrm{RH}$ (the average differences being $0.1^{\circ} \mathrm{C}$ and $3.0 \%$ of RH, respectively). The performance of the built-in materials was even smaller, as they were buffered by a plaster applied on the surface that reduced the influence of the environmental conditions. In this case, the maximal differences in the hygrothermal performance accounted only for $0.4^{\circ} \mathrm{C}$ and $2.2 \%$ of $\mathrm{RH}$. It can be therefore concluded that the utilisation of recycled aggregates in concrete is beneficial as it does not have negative effects on the performance while bringing other benefits such as economical and environmental. 
This research has been supported by the Grant Agency of the Czech Technical University in Prague under project No. SGS19/143/OHK1/3T/11 and by EMMAT project E-mobility and sustainable materials and technologies PPI/APM/2018/00027 financed by the Polish National Agency for Academic Exchange (NAWA).

\section{References}

1. A. D. Alsulaili, M. F. Al-Matrouk, R. A. Al-Baghli, A. F. Al-Enezi, Environ. Dev. Sustain. 22, 3371 (2020)

2. S. M. Khoshnava, R. Rostami, R. Mohamad Zin, D. Streimikiene, A. Mardani, M. Ismail, Int. J. Env. Res. Pub. He. 17 (2020)

3. S. Liu, C. Yang, W. Liu, L. Yi, W. Qin, Front. Env. Sci. Eng. 14 (2020)

4. E. Tang, Z. He, C. Chen, Y. Han, Compos. Struct. 241 (2020)

5. J. Li, Y. Zhang, Z. Zhang, H. Liu, J. Rui, Y. Li, Z. Chen, Mater. Lett. 268 (2020)

6. F. Peng, Y. Jiang, J. Feng, L. Li, H. Cai, J. Feng, J. Eur. Ceram. Soc. 40, 2480 (2020)

7. M. Maiti, M. Sarkar, S. Maiti, M. A. Malik, S. Xu, J. Clean. Prod. 255 (2020)

8. J. He, G. Zhang, S. Hou, C. S. Cai, J. Mater. Civil Eng. 23, 100 (2011)

9. S. Vaidya, E.N. Allouche, Smart Struct. Syst. 7, 27 (2011)

10. P. Gorak, P. Postawa, L. N. Trusilewicz, J. Clean. Prod. 256 (2020)

11. M. T. Rahman, A. Mohajerani, F. Giustozzi, Materials 13, (2020)

12. G. S. Kumar, Mag. Concrete Res. 72, 471 (2020)

13. R. K. Majhi, A. N. Nayak, J. Clean. Prod. 255 (2020)

14. R. Busic, M. Bensic, I. Milicevic, K. Strukar, Materials 13, (2020)

15. A. Crețu, C. Mattea, S. Stapf, I. Ardelean, Molecules 25, (2020)

16. A. C. Barboza-Chavez, L. Y. Gomez-Zamorano, J. L. Acevedo-Davila, Materials 13, (2020)

17. C. Gunasekara, Z. Zhou, D. W. Law, M. Sofi, S. Setunge, P. Mendis, J. Mater. Sci. 55, 6441 (2020)

18. V. Koci, J. Koci, J. Madera, Z. Pavlik, X. L. Gu, W.P. Zhang, R. Cerny, J. Build. Phys. 41, 497 (2018)

19. CSN 73 0540-2 (2011)

20. M. Qin, A. At-Mokhtar, R. Belarbi, Appl. Therm. Eng. 30, 2555 (2010)

21. N. Issaadi, A. Nouviaire, R. Belarbi, A. At-Mokhtar, Const. Build. Mater. 83, 237 (2015) 